\title{
Validation of a questionnaire for the evaluation of informal social support for the elderly: section 2.
}

Marcello Barbosa Otoni Gonçalves Guedes ${ }^{1,2}$ (D) Thais Sousa Rodrigues Guedes ${ }^{3}$ (D) André Luiz Lima' $\mathbb{1 D}$ Kenio Costa Lima' $\mathbb{I D}$

\section{Abstract}

Objective: The objective of the study was to carry out the factorial validation of the questionnaire for the evaluation of informal social support (ASI) for the elderly. Method: It is a descriptive, observational, quantitative type research. It was executed between August and December of 2016 in the municipality of Natal, Rio Grande do Norte and other locations in Brazil. In Inclusion criteria, were have age 60 or older and cognitive ability preserved. We performed Exploratory Factor Analysis (AFE). As criterion of exclusion of the items was adopted a reference value greater than or equal to 0.35 of factorial load and greater or equal to 0.5 of commonality per item. To determine the amount of retained factors, the criteria of own values $>1$, minimum cumulative explained variance of $60 \%$ and parallel Horn analysis were observed. Results: A sample of 259 elderly people from the five regions of Brazil was obtained. After AFE, 4 items were excluded due to the poverty of their factorial loads, remaining 20 items in 4 retained factors. Conclusion: The instrument has good psychometric properties, such as acceptable factor loads and excellent commonalities.
Keywords: Social Support. Health of the Elderly. Surveys and Questionnaires. Validation Studies. Factor Analysis. Statistics.

\footnotetext{
Universidade Federal do Rio Grande do Norte, Departamento de Odontologia, Programa de Pós-graduação em Saúde Coletiva. Natal, Rio Grande do Norte, Brasil.

2 Universidade Federal do Rio Grande do Norte, Departamento de Fisioterapia. Natal, Rio Grande do Norte, Brasil.

3 Universidade Federal do Rio Grande do Norte, Centro de Ciências da Saúde, Programa de Pós-graduação em Ciências da Saúde. Natal, Rio Grande do Norte, Brasil.
}

Correspondence

Marcello Barbosa Otoni Gonçalves Guedes 


\section{INTRODUCTION}

Population aging is a global reality and this demographic and epidemiological change is occurring in Brazil in an accelerated form. By 2050, there will be more than 30 million elderly people in the country ${ }^{13}$. These changes bring new demands for elderly care, based on a broader view of health issues. Understanding care for the elderly considering only aspects related to disease and neglecting important elements, such as social and psychological factors, may hamper integral and effective actions among this population ${ }^{4,5}$.

Considering the complexity of the understanding of the health-disease process of the elderly, in 2006 the Brazilian Ministry of Health established the National Policy for the Health of the Elderly Person (or PNSPI) as a priority action for this population, highlighting the active participation of such individuals in society, including continuous participation in social issues and the promotion of socio-educational and health resources aimed at this group ${ }^{6}$.

Studies describe how inadequate social conditions are directly associated with indicators of illness or adverse life conditions, and also influence the individual's emotional well-being ${ }^{7-12}$. From this perspective, Social Support (SS), especially informal support, plays an important role as a tool to support the health care of people aged 60 years or older ${ }^{13,14}$.

Some authors conceptualize SS as the accessible support for an individual through social ties with other individuals, groups and the community ${ }^{14}$. Squassoni et al. ${ }^{15}$ describe social support as a form of information that leads the individual to believe that they are loved, that there are people who care about them, that they are appreciated, valued, and affiliated with groups with mutual responsibilities, and that a differentiation can be made between formal support, formed by a network of professionals and diverse institutions, for example, and informal support ${ }^{10-16}$.

Informal Social Support (ISS) refers to any support received from a network of those close to the individual, usually consisting of family members, friends or neighbors, and which can involve diverse aspects such as social interaction, support in dayto-day activities, and material and financial support, among others ${ }^{8-16}$. These aspects can form the latent dimensions of ISS.

The importance of SS is highlighted when informal support networks are considered an essential component for ensuring autonomy, positive self-assessment, greater mental health and life satisfaction ${ }^{13}$. Félix et al. ${ }^{7}$, in an integrative literature review, identified a lack of social support as one of the predominant factors for suicide attempts in Brazil, among the overall population, agreeing with findings from another country ${ }^{16}$. For many elderly persons, ISS is the most prominent source of support in their lives.

For the efficient intervention of ISS it is important that the evaluation of this support uses instruments of recognized validity. However, the measurement of this construct has been approached from different perspectives by many researchers, using different assessment tools, and often does not meet minimum validation requirements ${ }^{17-19}$. In addition to this lack of or insufficient use of appropriate instruments, the multidimensionality of the social support construct and the lack of distinction between formal social support (FSS) and ISS have contributed to difficulties in the construction of appropriate instruments, meaning those that are used are excessively generic, making it difficult to compare results between studies, and often leading to imprudent or incomplete evaluations ${ }^{19}$.

Regarding the aforementioned validation process, in 2014 the American Educational Research Association (AERA), the American Psychological Association (APA), and the National Council on Measurement in Education (NCME) $)^{19}$ proposed the development of instruments which included, among other steps, evidence of validity based on content, the response process and internal structure.

One of the ways to statistically examine the internal structure of an instrument is factor analysis ${ }^{20}$. This is a multivariate statistical analysis method that operationalizes abstract concepts, which are difficult to measure, into observable variables, which can be reduced to smaller quantities and a reduced number of factors, facilitating interpretation ${ }^{21-23}$. This technique considers the correlation between the items analyzed, grouping them into factors and limiting the number of uncorrelated variables, increasing the reliability of the instrument ${ }^{24}$. 
Factor Analysis, especially exploratory analysis, assumes that the evaluated construct is not well defined and is based on the construction of the structure of the instrument analyzed in dimensions, with the creation of a smaller set of variables than the original set ${ }^{22-25}$. In view of the above, the objective of this section is to analyze the factorial validity of the Informal Social Support Questionnaire for the Elderly through Exploratory Factor Analysis (EFA).

\section{METHOD}

A descriptive, observational, quantitative type research was performed. The present study was undertaken from January to December 2016, as part of the "Construction and validation of a social support scale for the elderly" project. The present study contemplated the factorial validity stage, based on Exploratory Factor Analysis, focusing on the previous steps in the construction of the instrument, among them, the proposition of items based on a literature review described in a manuscript published by Guedes et al. ${ }^{17}$, validity based on content and on the response process, debated in the first section of this collectane ${ }^{26}$.

Data collection took place in person or virtually with a population aged 60 years or older from the city of Natal, in an elderly persons association, a public consultation center and a municipal park, or in other locations in Brazil via e-mail, using the SurveyMonkey® tool. When carried out in person, the participants signed the informed consent form while when contact was virtual, they agreed to participate in the study by clicking on the "I agree" option of the questionnaire.

The inclusion criteria for the study participants were 60 years of age or older, with preserved cognitive levels (no clinical diagnosis of cognitive deficit), capable of answering the questions proposed. Whenever the respondent had no schooling, the presence of a previously trained interviewer was mandatory. For the sample calculation, the total number of respondents followed a minimum proportion of 10 for each variable included in the instrument (24 items), giving a total of 259 individuals, following the criteria described by Hair et al. ${ }^{22}$.
Exploratory Factor Analysis was performed using the M PLUS Version $7 \circledR$ statistical program. Variable clustering (type $\mathrm{R}$ ) and factor extraction were performed with common factor analysis, using Geomin oblique rotation. The tetrachoric/ polychoric matrix was initially run with only one factor and all 24 original items. To interpret the rotated factor matrix, criteria were adopted to evaluate whether the items should be maintained. The initial exclusion criterion of the item was based on guidelines for the identification of significant factor loadings based on sample size, which is 0.35 for populations between 250 and 349 subjects, according to Hair et al. ${ }^{22}$. Items with factor loadings less than 0.35 were excluded. The significance was based on a level of 0.05 and a power of $80 \%$, and standard errors considered twice that of conventional correlation coefficients. Communalities less than 0.50 , for the most part, were considered as not being sufficiently explained, and these items were evaluated case by case (after determining the factors). Variables with significant loadings in more than one factor (cross loadings) were evaluated for their inclusion in a given factor, through their intensity of significance and conceptual representation over the given domain (after determining the factors).

The next step was to determine the number of factors. For this, certain criteria were adopted. Only factors with eigenvalues above 1 were extracted. The ideal cumulative Variance considered was equal to or greater than $60 \%$ for the number of possible Factors. For the Horn Parallel Analysis criterion for the extraction of Factors, a graphical analysis of the variance curve was performed, establishing the beginning of horizontalization or abrupt drop as a reference point ${ }^{22}$.

As the first proposal of reference values for the instrument, values were assigned to the items in proportion to the common variance explained for their factors. "Yes" responses were assigned the maximum values ( 2 or 4 , depending on the item) referring to the item and "no" answers were assigned a score of zero. The reference values of the overall instrument and the dimensions were determined by the median, as the distribution of the sample was not considered normal. The total sample of 259 subjects was considered for the definition of means and medians. 
The project was approved by the Ethics Research Committee of the Hospital Universitário Onofre Lopes, under opinion number 1.644.533. The present study complies with Resolutions No 196/96 and No 466/2012, of the National Health Council (or CNS).

\section{RESULTS}

In terms of descriptive analysis, the total sample corresponded to 259 respondents, of whom $73.15 \%$ were women and $26.85 \%$ were men. Regarding educational level, $34.75 \%$ had an elementary level education, $23.17 \%$ a secondary level education, and $22.01 \%$ a higher level education. A total of $11.58 \%$ had no schooling and $8.49 \%$ had a postgraduate education. Responses were obtained from the five regions of Brazil, most of which were from the northeast $(85.33 \%)$ and the southeast $(12.36 \%)$, followed by other regions $(2.32 \%)$,.

Regarding the determination of the reference values for the instrument, based on the explained common variance of each factor, 20 possible points were assigned to dimension 1; 14 possible points to dimension 2; 6 possible points to dimension 3; and 10 possible points to dimension 4 . The overall mean among the respondents was 40.01 and the overall median was 42; in factor one, 20 points; in factor two, 10 points; in factor three, 6 points; and in factor four, 8 points.

Table 1 shows all the items with their respective factor loadings with one factor extracted. Table 2 shows the common variance explained for the possible factors and their cumulative common variance percentages.

Figure 1 shows the eigenvalue and Horn graph with simulation for the parallel analysis criterion. Table 3 shows the distribution of factor loadings and commonalities with four retained factors. Table 4 shows the items distributed in the four retained factors and the results of medians and means by domains and overall.

Table 1. Factor loadings of the 24 original items of the Informal Social Support Questionnaire for the Elderly, with only one Factor extracted. Natal, Rio Grande do Norte, Brazil, 2018

\begin{tabular}{|c|c|}
\hline Items & Factor loadings \\
\hline 1 & $0.746^{*}$ \\
\hline 2 & $0.425^{*}$ \\
\hline 3 & $0.576^{*}$ \\
\hline 4 & $0.718^{*}$ \\
\hline 5 & $0.603^{*}$ \\
\hline 6 & $0.587^{*}$ \\
\hline 7 & $0.314 * *$ \\
\hline 8 & $0.480^{*}$ \\
\hline 9 & $0.725^{*}$ \\
\hline 10 & $0.447 *$ \\
\hline 11 & $0.661^{*}$ \\
\hline 12 & $0.744^{*}$ \\
\hline 13 & $0.693^{*}$ \\
\hline 14 & $0.591^{*}$ \\
\hline 15 & $0.487^{*}$ \\
\hline $16 * *$ & $0.312 * *$ \\
\hline $17 * *$ & $0.292 * *$ \\
\hline $18 * *$ & $0.270 * *$ \\
\hline
\end{tabular}


Continuation of Table 1

\begin{tabular}{ll}
\hline Items & Factor loadings \\
\hline 19 & $0.620^{*}$ \\
20 & $0.624^{*}$ \\
21 & $0.452^{*}$ \\
22 & $0.628^{*}$ \\
23 & $0.691^{*}$ \\
24 & $0.743^{*}$ \\
\hline
\end{tabular}

*Significant for $p<0.05 ; * *$ Items and values with factor loadings lower than 0.35 .

Table 2. Number of Factors extracted, their own values, percentage explained by the common variance for each possible factor and percentage of the cumulative common variance of the Informal Social Support Questionnaire for the Elderly. Natal, Rio Grande do Norte, Brazil, 2018.

\begin{tabular}{llll}
\hline Factor Extracted & Own values & $\begin{array}{l}\text { Percentage explained by } \\
\text { common variance }\end{array}$ & $\begin{array}{l}\text { Percentage of cumulative } \\
\text { common variance }\end{array}$ \\
\hline 1 & 7.816 & $38.7 \%$ & $38.7 \%$ \\
2 & 2.374 & $11.8 \%$ & $50.5 \%$ \\
3 & 1.621 & $8.0 \%$ & $58.5 \%$ \\
4 & 1.368 & $\mathbf{6 . 8} \%$ & $\mathbf{6 5 . 3} \%$ \\
5 & 1.121 & $5.6 \%$ & $70.9 \%$ \\
6 & 0.943 & $4.7 \%$ & $75.6 \%$ \\
7 & 0.794 & $3.9 \%$ & $79.5 \%$ \\
8 & 0.777 & $3.8 \%$ & $83.3 \%$ \\
9 & 0.754 & $3.7 \%$ & $87.0 \%$ \\
10 & 0.599 & $3.0 \%$ & $90.0 \%$ \\
11 & 0.563 & $2.8 \%$ & $92.8 \%$ \\
12 & 0.449 & $2.2 \%$ & $95.0 \%$ \\
13 & 0.367 & $1.8 \%$ & $96.8 \%$ \\
14 & 0.341 & $1.7 \%$ & $98.5 \%$ \\
15 & 0.188 & $0.9 \%$ & $99.4 \%$ \\
16 & 0.128 & $0.6 \%$ & $100 \%$ \\
17 & 0.000 & $0.00 \%$ & \\
18 & -0.017 & & \\
19 & -0.086 & & \\
20 & -0.100 & & \\
\hline Total Own Value & 20.203 & & \\
\hline
\end{tabular}

Number of factors extracted and percentage of minimum acceptable cumulative common variance and with own values $>1$ are in bold. 


\section{Own values and tetrachoric/polychoric matrix}

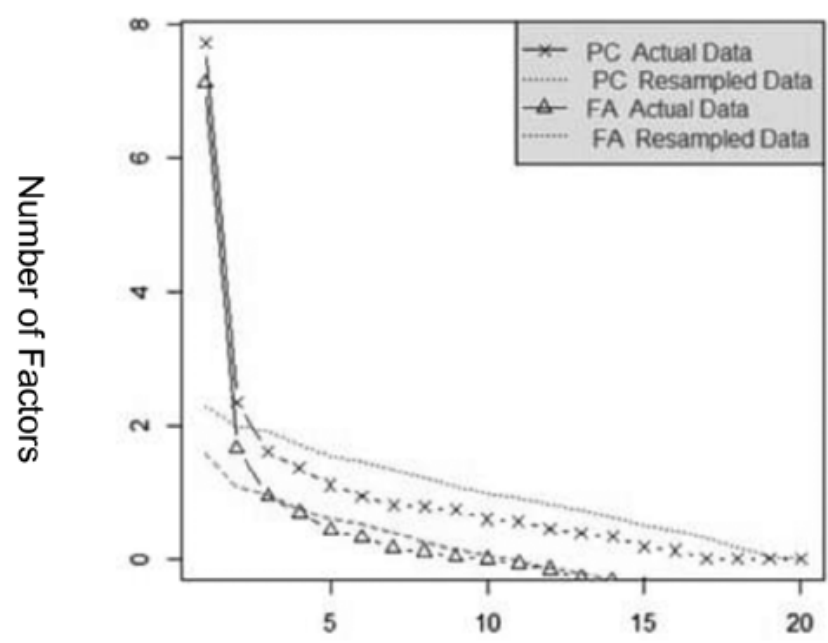

Figure 1. Graph of own values and factor simulation for Horn Parallel Analysis criterion of Informal Social Support Questionnaire for the Elderly. Natal, Rio Grande do Norte, Brazil. 2018.

Table 3. Matrix of rotational factor loadings with four Extracted Factors, 20 items and their respective commonalities of the Informal Social Support Questionnaire for the Elderly. Natal, Rio Grande do Norte, Brazil, 2018.

\begin{tabular}{llllll}
\hline Factors/Factor loadings of Items & Factor 1 & Factor 2 & Factor 3 & Factor 4 & Commonalities \\
\hline 1 & $0.571^{* *}$ & 0.038 & $0.499^{*}$ & -0.013 & 0.842 \\
2 & 0.041 & $0.653^{* *}$ & -0.046 & 0.028 & 0.903 \\
3 & $0.650^{* *}$ & -0.054 & -0.235 & 0.239 & 0.878 \\
4 & $0.495^{* *}$ & 0.239 & 0.385 & -0.065 & 0.891 \\
5 & $0.978^{* *}$ & -0.379 & -0.012 & 0.056 & 0.838 \\
6 & $0.584^{* *}$ & -0.009 & 0.041 & 0.135 & 0.892 \\
8 & 0.224 & $0.351^{* *}$ & 0.039 & 0.093 & 0.920 \\
9 & 0.442 & 0.100 & -0.042 & $0.500^{* *}$ & 0.872 \\
10 & -0.088 & $0.886^{* *}$ & -0.196 & 0.036 & 0.851 \\
11 & 0.316 & $0.547^{* *}$ & 0.144 & -0.040 & 0.873 \\
12 & $0.453^{*}$ & $0.484^{* *}$ & 0.167 & -0.079 & 0.881 \\
13 & $0.386^{*}$ & $0.526^{* *}$ & 0.029 & 0.060 & 0.903 \\
14 & 0.035 & -0.068 & $0.817 * *$ & 0.428 & 0.851 \\
15 & 0.111 & -0.163 & 0.265 & $0.511^{* *}$ & 0.902 \\
19 & 0.044 & $0.332^{*}$ & -0.012 & $0.679 * *$ & 0.852 \\
20 & 0.124 & -0.018 & 0.110 & $0.703^{* *}$ & 0.877 \\
21 & 0.254 & 0.100 & $0.353^{* *}$ & -0.005 & 0.848 \\
22 & 0.014 & 0.109 & $0.585^{* *}$ & $0.460^{*}$ & 0.885 \\
23 & 0.309 & 0.208 & -0.045 & $0.518^{* *}$ & 0.901 \\
$* 4$ & 0.059 & $0.681^{* *}$ & 0.351 & 0.078 & 0.862 \\
\hline
\end{tabular}

*Significant for $p<0.05$; ** factor loadings to determine the Factor in which the item was assigned. 
Table 4. Final questionnaire with items and factors. Values assigned to items and instrument. Arithmetic means and standard deviation per item. Means by Factor. Overall mean and Median of the instrument, after interviews with the elderly. Natal, Rio Grande do Norte, Brazil, 2018.

\begin{tabular}{|c|c|c|c|}
\hline Items and Factors & $\begin{array}{l}\text { Value attributed } \\
\text { to item }\end{array}$ & $\begin{array}{l}\text { Arithmetic Mean } \\
\text { Obtained }\end{array}$ & $\begin{array}{l}\text { Standard } \\
\text { Deviation }\end{array}$ \\
\hline \multicolumn{4}{|l|}{ Composition and extension of social network } \\
\hline 1. Can you count on people close to you? & 4 & 3.86 & $( \pm 0.73)$ \\
\hline 3. Do you have a friend who you see often? & 4 & 3.32 & $( \pm 1.50)$ \\
\hline $\begin{array}{l}\text { 4. Do you have anyone in your family you can count } \\
\text { on and who lives nearby? }\end{array}$ & 4 & 3.42 & $( \pm 1.40)$ \\
\hline 5. Do you have a friend who lives nearby? & 4 & 3.29 & $( \pm 1.53)$ \\
\hline $\begin{array}{l}\text { 6. Do you have a neighbor who you can count on } \\
\text { when you need them? }\end{array}$ & 4 & 3.14 & $( \pm 1.64)$ \\
\hline Factor 1 Median & 20 points & & \\
\hline
\end{tabular}

Instrumental support and availability

2. Do you live with a lot of people?

$2 \quad 0.55$

8. Do you have frequent visitors?

10. Do you have someone to help with household chores?

11. Do you have someone to help you leave the house

if you need them?

12. Do you have someone to help you if you are sick or bedridden?

13. If you are in financial difficulty is there someone who can help you?

24. Do you have a family member who helps with your care if you need it?

Factor 2 Median 10 points

Reciprocity and longitudinality

14. Do you participate in any family decisions?

21. Has the help you have had or would have had in throughout your life?

Factor 3 Median 6 points

Emotional support and social participation

9. Do you have someone to talk to?

$2 \quad 1.83$

15. Do you participate in decisions among friends?

20.89

19. Do you share leisure time with someone?

$2 \quad 1.70$

20. Is your social contact with others permanent?

$2 \quad 1.62$

23. When you are sad or miss someone or something is there someone you can talk to about it?

\begin{tabular}{lc} 
Overall Factor 4 Mean & 8 points \\
\hline Total Mean obtained in interviews & $40.01( \pm 8.20)$ \\
Median (reference value) & 42 points \\
Total value attributed to instrument & 50 points \\
\hline
\end{tabular}




\section{DISCUSSION}

As the validation of questionnaires is a systematized and continuous process of actions, factorial validation represents an important step in this process ${ }^{20,21}$ and is at the center of the discussion of this section of an as yet unfinished collection ${ }^{17,26}$. Factor analysis is an important tool for evaluating the structure of correlations between variables. These variables can be clustered into factors when they are closely correlated, thus forming latent dimensions (identified in this study by type $\mathrm{R}$ factorial analysis) that facilitate the understanding of the construct ${ }^{21,22,24}$.

Descriptive analysis revealed good variability of the subjects of the sample. There were representatives from elementary and high school, higher and postgraduate educational levels. Elderly persons with an elementary school level of education predominated. Respondents from the five regions of Brazil were obtained, although most were from the northeast of the country. This was partly due to the addition of data from face-to-face interviews that took place in the city of Natal. The predominant gender was female, but there was a considerable absolute sample of men.

Regarding the choice of tools for factorial analysis, rotation of factors allowed the obtaining of a standard that was simpler from an interpretive and theoretically significant perspective. The choice of oblique rotation was due to the need to allow the correlation of the factors related to informal social support, considering the variables chosen ${ }^{22,24}$.

Four questions had very poor factor loadings and were eliminated after rotation based on one retained factor. It is possible that misunderstandings in the meaning of these questions by the respondents led to a number of undesirable random responses, interfering with their power to explain the construct and correlation with other variables. Another possibility is that these questions are of debatable relevance to the overall explanation of informal social support, as they may be explained by other questions.

One challenge in research using the factorial analysis method is the choice of the number of factors. A balance is sought between parsimony and the significance of information. Overestimation of the quantity of factors can lead to the production of an exaggerated number of constructs, with a number of excessive and superfluous dimensions with reduced explanatory power. In contrast, a very small number of retained factors could result in a significant loss of information ${ }^{23,25,27-30}$.

Analyzing one of the parameters adopted in this research, the "latent root criterion" (eigenvalues $>1$ ), Costello and Osborne ${ }^{28}$ demonstrated that it tends to overestimate the number of factors retained. In addition, Fava and Velicer ${ }^{29}$ demonstrated that such overestimation tends to occur mainly when the factor loadings of the items are low. The factor loadings of the items of this study met the acceptable requirements for the size of the respondent sample. However, the low number of optimal factor loadings (above 0.70 ) and the presence of factor loadings close to the desired minimum limit ${ }^{23}$ were indicative of a small number of factors.

Given the above, we believe that the choice of four factors met a reasonable percentage of the cumulative variance explained and minimized the risk of factor overestimation, achieving a balance between parsimony and significance of information. This choice was also supported by the findings of the Horn Parallel Analysis ${ }^{25}$.

Following the choice to exclude four items and the determination of four factors, the matrix was rotated again. All factor loadings were significant and acceptable for the pre-determined parameters. Significant factor loadings demonstrate a correlation between the items and their factors. In addition, the commonalities of the items, when four factors were considered, were excellent (lowest commonality of 0.838). The commonalities represent the amount of variance explained by each variable, demonstrating the close correlation of one variable to the others (shared variance). Crossed factor loadings occurred in small numbers and inclusion in a determined factor was always chosen, based on the level of significance, without the need for conceptual justifications ${ }^{22,25}$.

After evaluating the significance of the factor loadings of each item for their proper clustering, the next step was to label the factors, that is, to determine the latent dimensions of each factor. This step is not 
determined by the computer program but by the researchers involved. A good theoretical foundation in the understanding of the construct studied and the real aspects that define it is therefore important ${ }^{23}$.

In order to choose the labels, items with larger factor loadings were considered to have greater importance in the definition of names, as well as the theoretical-methodological approaches addressed in previous studies. Thus, the dimensions of: Composition and Extension of Social Network; Instrumental Support and Availability; Reciprocity and Longitudinality; Emotional and Social Participation were determined.

Some specific dimensions of social support are discussed in literature and support the classifications chosen for the latent dimensions of this study. Studies point to the importance of evaluating social network composition for ISS and highlight some important components, among them, family and friend ${ }^{16,31}$. The importance of evaluating the extension of the social support network for the elderly is also repeatedly mentioned $^{31}$.

The category instrumental support as an integral part of SS has been the subject of both descriptive research and instrument validation studies ${ }^{32,33}$. Understanding the availability of people close to them, including for day-to-day tasks, can make the elderly feel valued and that they have strong social ties with their support network ${ }^{16}$

Reciprocity can lead to a sense of solidarity ${ }^{33,34}$. Engagement in family decisions, for example, can be a source of this feeling. The theme of longitudinality, however, is still little studied with regard to informal social support. However, aspects of continuity of care have been found to be positive for successful care network models and health outcomes ${ }^{32}$. These factors value the importance of longitudinality as a component for assessing informal social support for the elderly.

Emotional aspects are intimately linked to social interaction and participation and are therefore integral parts of successful ISS and are dimensions constantly referred to in studies on this theme ${ }^{34,33}$. The World Health Organization (WHO) proposes in its International Classification of Functioning ${ }^{35}$ the evaluation of social participation for support and relationships.

Regarding the determination of the values for each dimension, factor 1 was the only factor where its items scored the most, with a total of 20 points attributed, that is, $40 \%$ of the value of the instrument. This value was very close to the percentage of variance explained for this factor, thus justifying a considerably higher level than the others. The suggested reference values, both overall and by dimensions, represent only an initial proposal. As the sample was not normally distributed, overall and factor medians were used as reference points. Studies with a more refined design, in terms of accuracy, can delimit more precise cutoffs for this instrument, evaluating criteria such as sensitivity and specificity, for example.

Even though most of the items are employed with greater magnitude in the elderly population, the application of this instrument in other populations should not be ruled out, considering its broad approach in dimensions common to several vulnerable groups. This instrument can therefore be an important tool for tracking unsuccessful informal social support, and can be applied in several health services, especially in primary care, seeking to use social networks to support the integral care of people, enhancing the desired results.

Limitations of the study include the fact that, while it included respondents from all regions of the country, the sample was concentrated mostly in the northeast and southeast regions, thus reducing the desirable cultural variability. Part of the respondents answered the questionnaire at distance, which may have favored a greater number of random responses, enhancing the possibility of response bias. A direct evaluation of the cognitive ability of the respondents was not performed, which could increase the risk of elderly people with cognitive deficits answering the questionnaire, impairing the analysis and interpretation of the data.

As informal social support can be considered a multidimensional construct, it is difficult to measure all its aspects and determinants. However, the social support of information is repeatedly highlighted in the literature and was not contemplated in this 
instrument. It is prudent to keep in mind the importance of certifying the psychometric qualities of this instrument in other populations and from the perspective of other statistical tools, which can be discussed in later sections.

\section{CONCLUSION}

From the evaluation of the results of Exploratory Factor Analysis, the Informal Social Support Questionnaire for the Elderly exhibited good psychometric properties, such as acceptable factor

\section{REFERENCES}

1. Furtado LFV, Araújo PM, Soares FVS, Brito VM, Sousa LG, Yoshioka FKN, et al. Epidemiologia do envelhecimento: dinamização, problemas e consequências. Rev Kairós. 2012;15(2):55-69.

2. Veras R. Envelhecimento populacional contemporâneo: demandas, desafios e inovações. Rev Saúde Pública. 2009;43(3):548-54.

3. Lebrão ML. Epidemiologia do envelhecimento. BIS, Bol Inst Saúde. 2009;47:23-6.

4. Paim JS, Almeida Filho N. Conceitos de Saúde: atualização de debate teórico metodológico.In: Saúde Coletiva: teoria e prática. Rio de Janeiro: MedBook; 2014. Cap. 2. p. 203-09.

5. Backes MTS, Rosa LM, Fernandes GCM, Becker SG, Meirelles BHS, Santos SMA. Conceitos de saúde e doença ao longo da história sob o olhar epidemiológico e antropológico. Rev Enferm. 2009;17(1):111-7.

6. Brasil. Portaria MS/GM no 2.528 de 19 de outubro de 2006. Aprova a Política Nacional de Saúde da Pessoa Idosa. Brasília, DF: MS, 2006.

7. Félix TA, Oliveira EN, Lopes MVO, Parente JRF, Dias MSA, Moreira RMM. Fatores de risco para tentativa de suicídio: produção de conhecimento no Brasil. Rev Contexto Saúde. 2016;16(31):173-85.

8. Johnson ER, Carson TL, Affuso O, Hardy CM, Baskin ML. Relationship between social support and body Mass index among overweight and obese african american women in the Rural Deep South, 2011-2013. Prev Chronic Dis. 2014;11(224):1-9. loadings and excellent commonalities. The twenty items that compose the instrument were distributed among four retained factors: Composition and Extension of the Social Network; Instrumental Support and Availability; Reciprocity and Longitudinality; and Emotional Support and Social Participation.

The suggested reference value for successful informal social support for the elderly was 42 points. Validation studies for the improvement of this questionnaire, in new populations and applying techniques of Confirmatory Factor Analysis and accuracy, are important.

9. Melchiorre MG, Chiatti C, Lamura G, TorresGonzales F, Stankunas M, Linder J. Social support, socio-economic status, health and abuse among older people in seven european countries. PLos ONE. 2013;8(1):548-56.

10. Boen H, Dalgard OS, Bjertness E. The importance of social support in the associations between psychological distress and somatic health problems and socio-economic factors among older adults living at home: a cross sectional study. BMC Geriatr. 2012;12(27):1-12.

11. Eisele M, Zimmermann T, Köhler M, Wiese B, Heser $\mathrm{K}$, Tebarth $\mathrm{F}$, et al. Influence of social support on cognitive change and mortality in old age: results from the prospective multicentre cohort study AgeCoDe. BMC Geriatr. 2012;12:1-9.

12. Maia CML, Castro FV, Fonseca AMG, Fernández MIR. Redes de apoio social e de suporte social e envelhecimento ativo. Rev INFAD Psicol. 2016;1(1):293-303.

13. Luchesi BM, Brito TRP, Costa RS, Pavarini SCL. Suporte social e contato intergeracional: estudando idosos com alterações cognitivas. Rev Eletr Enferm. 2015;17(3):1-8.

14. García-Martín MA, Hombrados-Mendieta I, GómezJacinto L. A Multidimensional Approach to Social Support: the Questionnaire on the Frequency of and Satisfaction with Social Support (QFSSS). An Psicol. 2016;32(2):501-15. 
15. Squassoni CE, Matsukura TS, Panúncio-Pinto MP. Versão brasileira do Social Support Appraisals: estudos de confiabilidade e validade. Rev Ter Ocup. 2016;27(1):1-11.

16. Kleiman EM, Liu RT. Social support as a protective factor in suicide: Findings from two nationally representative samples. J Affect Disord. 2014;150(2): 540-5.

17. Guedes MBOG, Lima KC, Caldas CP, Veras RP. Apoio social e o cuidado integral à saúde do idoso. Physis. 2017;27(4):1185-204.

18. Gonçalves TR, Pawlowski J, Bandeira DR, Piccinini CA. Avaliação de apoio social em estudos brasileiros: aspectos conceituais e instrumentos. Ciênc Saúde Colet. 2011;16(3):1755-69.

19. American Educational Research Association; American Psychological Association (APA); National Council on Measurement in Education (NCME). The standards for educational and psychological testing. New York: American Educational Research Association; 2014.

20. Figueiredo Filho DB, da Silva Júnior JA. Visão além do alcance: uma introdução à análise fatorial. Opin Pública. 2010;16(1):160-85.

21. Viera PRC, Ribas JR. Análise Multivariada com uso do SPSS. Rio de Janeiro: Ciência Moderna; 2011.

22. Hair JF, Black WC, Babin BJ, Anderson RE, Tatham RL. Análise multivariada de dados. 6. ed. São Paulo: Bookman; 2009.

23. Pasquali L. Psicometria. Rev Esc Enferm USP. 2009;43(Esp):992-9.

24. Damásio BF. Uso da análise fatorial exploratória em psicologia. Aval Psicol. 2012;11(2):213-28.

25. Fávero LP. Análise de dados: modelagem multivariada para tomada de decisões. Rio de Janeiro: Elsevier; 2009.
26. Guedes MBOG, Lima KC, Lima AL, Guedes TSR. Validation of a questionnaire for the evaluation of informal social support for the elderly: section 1 . Rev Bras Geriatr Gerontol. 2018;21(6):647-56.

27. Streiner LD, Kottner J. Recommendations for reporting the results of studies of instrument and scale development and testing. J Adv Nurs. 2014;70(9):1970-79.

28. Costello AB, Osborne JW. Best practices in exploratory factor analysis: four recommendations for Getting the Most From Your Analysis. Pract Assess Res Eval. 2005;10(7):173-8.

29. Fava JL, Velicer WF. The effects of over extraction on factor and component analysis. Multivariat Behav Res. 1992;27(3):387-415.

30. Shumaker SC, Susan KF, Debra KM, Misook LC. Psychometric Properties of the Multidimensional Scale of Perceived Social Support in Patients With Heart Failure. J Nurs Meas. 2017;25(1):90-102.

31. Gouveia OMR, Matos AD, Schouten MJ. Redes sociais e qualidade de vida dos idosos: uma revisão e análise crítica da literatura. Rev Bras Geriatr Gerontol., 2016;19(6):1030-40.

32. Veras RP, Caldas CP, Motta LB, Lima KC, Siqueira RC, Rodrigues RTSV, et al. Integration and continuity of care in health care network models for frail older adults. Rev Saúde Pública. 2014;48(2):357-65.

33. Pinto JM, Neri AL. Trajetórias da participação social na velhice: uma revisão sistemática da literatura. Rev Bras Geriatr Gerontol. 2017;20(2):260-73.

34. Hobbs WR, Burke M, Christakis NA, Fowler JH. Online social integration is associated with reduced mortality risk. PNAS. 2016;113(46):12980-4.

35. Organização Mundial de Saúde. Classificação Internacional de Funcionalidade, Incapacidade e Saúde. [S. 1.]: OMS; 2003. 